\title{
Frictionless shear at great depth and other paradoxes of hard rocks
}

\author{
Tarasov, B.G. and Randolph, M.F. \\ The University of Western Australia, Australia
}

\begin{abstract}
Shearing with very low friction is regarded as responsible for the high energy release from deep-seated earthquakes and rock bursts in deep underground mines, but in spite of considerable attention to the problem no consensus of opinion has been reached regarding the physical explanation for the low friction. Alternative hypotheses include melting, lubrication, excess pore pressure, velocity effects and vibration at the interface. Here, however, we demonstrate that under high confining stresses shear fractures developing in pristine hard rocks can exhibit dramatically low shear resistance over a certain displacement range, before the residual frictional strength is mobilised, due to the intrinsic nature of the fault structure. This feature is due to a special fault structure formed during the fault development. The discovered phenomenon can explain a number of anomalies observed in the field and laboratory conditions, but in particular the very high energy released from deep-seated earthquakes and rockbursts.
\end{abstract}

Shear fracture, low friction, intense violence, rockburst, earthquake.

\section{Introduction}

Observations of unstable fracture processes in hard rock under laboratory conditions [1], in deep mines (from rockbursts) [2], and during deep-seated earthquakes [3-5], show abnormally intense violence, which has been explained by very low friction following fracture. A number of mechanisms have been proposed that might account for such low friction during dynamic shearing, such as: local melting within the shear band [3]; lubrication [4]; trapped high excess pore pressures [5]; the effect of shearing at very high strain rates [6]; and transverse vibration at the shearing interface [2]. However, there is still no consensus regarding the primary mechanism for the very low friction. Hickman in his review article [7] summarised the current situation in this sphere of knowledge: "As this weakness is contrary to traditional views of fault strength based upon laboratory experiments, the Earth science community is left in the awkward position of having no generally accepted paradigm for the mechanical behavior of faults at depth”.

The present paper draws attention to the fact that despite the comprehensive study of the frictional rock behaviour after failure [8-12] the transition mechanism from intact cohesive strength into residual strength during development of the shear fracture has still not been studied comprehensively for pristine hard rocks (e.g. granite, basalt, dolerite, diabase, quartzite, etc) failed under high confining pressures in excess of 50 MPa. The 
difficulty is that these rocks respond in such a brittle manner under high confining pressure [1] that even modern stiff and servo-controlled loading systems are unable to control the fracture process. The existing models of shear fracture development [13-18] are based on experimental results obtained at relatively low confining pressures where the behaviour of pristine hard rocks is less brittle [19] or on more ductile rocks [13]. So, the transition mechanism from intact to residual strength is still essentially unexplored under conditions of the extreme brittleness that hard rocks exhibit at high confining pressures.

Here we demonstrate that shear fractures developed in pristine hard rocks under high confining stresses can exhibit dramatically low shear resistance over a certain displacement range, due to the special fault structure. The displacement range over which the friction remains very low (theoretically as low as zero) is linked to the width of the shear zone, after which the residual shear strength is mobilized. The discovered phenomenon can explain a number of anomalies observed in the field and laboratory, in particular the very high energy released from deep-seated earthquakes and rockbursts. Increasing brittleness with increasing confining pressure, instead of the expected increase in ductility, which has proved a paradoxical feature of hard rocks [1], follows logically from the fault structure identified. A practical outcome from this work is the improved understanding and quantification of earthquake and rockburst mechanisms that involve shear rupture.

\section{Experiments}

Experiments were conducted on dolerite specimens obtained from a depth of $712 \mathrm{~m}$ using standard rock-coring methods from a seismically active gold mine (Junction Mine) in Australia. The cylindrical specimens were $36 \mathrm{~mm}$ in diameter and $72 \mathrm{~mm}$ long and all were monolithic without any visible defects. The grain size ranged from 0.05 to $0.7 \mathrm{~mm}$. Both ends of each specimen were ground to achieve a parallelism of better than $0.02 \mathrm{~mm}$.

A super-stiff servo-controlled triaxial testing machine designed and fabricated at the University of Western Australia was used for the testing program (for details see www.cofs.edu.au). The machine involves a monolithic loading frame with stiffness of 20 $\mathrm{MN} / \mathrm{mm}$. The calibrated total stiffness of the machine for specimens loaded in the pressure cell is $2.2 \mathrm{MN} / \mathrm{mm}$. The apparatus incorporates a unique wedge mechanism which allows most of the elastic energy accumulated within the hydraulic actuator to be isolated from the sample during the post-peak stage of specimen deformation. This can increase the loading stiffness up to a maximum of $4 \mathrm{MN} / \mathrm{mm}$. The machine loading capacity is $2000 \mathrm{kN}$ and the maximum confining pressure provided by silicone oil is 200 MPa. Servo-control of load, strain and confining pressure is provided.

Each specimen was placed between two steel end-caps and sealed by a rubber sleeve. An axial extensometer and two lateral extensometers (located orthogonally) were fixed to the specimen. The axial transducer was used to control the strain rate between 5 and 10 microstrain/second prior to the peak strength. Signals from one of the lateral transducers most suitably oriented to the developing shear fracture were used to control the test (where possible) in the post-peak region. A low aspect ratio load cell, comprising a solid steel cylinder with diameter of $40 \mathrm{~mm}$ and length of $50 \mathrm{~mm}$, was located within the pressure chamber immediately below the specimen lower cap. The output from the load 
cell was provided by strain gauges glued close to the cylinder axis within special small holes drilled horizontally into the load cell, providing excellent linearity with load.

Two independent acquisition systems were used for recording signals in static and dynamic (unstable failure) regimes. The dynamic system was triggered when spontaneous fracture occurred. The frequency response of the dynamic recording system was steady up to $200 \mathrm{kHz}$, which was the maximum sampling rate used in the tests.

The specimens were tested at confining pressures $\sigma_{3}$ of $0,10,30,60,75,100$ and $150 \mathrm{MPa}$ under normal air-conditioned laboratory conditions. Stress-strain curves for all specimens are shown in Figure 1. The vertical axis here represents differential stress $\Delta \sigma=$ $\sigma_{1}-\sigma_{3}$. As expected, the peak strengths increase with confining stress, following a typical curved strength envelope. Two important features of the post-peak response, typical for hard rocks, were also observed in these tests, namely (a) the increasing brittleness, and (b) the increasing fracture violence, with increase in confining pressure. At $\sigma_{3}=0$ and $10 \mathrm{MPa}$, the specimens failed with the formation of a number of long tensile cracks as illustrated in Figure 1. The post-peak response was controlled easily using the stiff testing machine, because that part of the curve has a negative slope, indicating relatively large specific energy consumption during the strength degradation.

Figure 1

The failure mode for the specimens tested at higher confining pressures was different, comprising a single shear plane inclined at an angle $\alpha$ of $25^{\circ}$ to $30^{\circ}$ to the specimen axis. The rock behaviour here is characterized by greater brittleness due to significant decrease in the specific energy consumption during strength degradation. The post-peak branch now has a positive slope initially. Despite this fact the loading system managed to maintain post-peak stability in the test at $\sigma_{3}=30 \mathrm{MPa}$, responding to changes in one of the lateral extensometers. However, at $\sigma_{3}=60$ and $75 \mathrm{MPa}$ the brittleness became so high that it was possible only to maintain stability near the start of the post-peak response, after which violent failure occurred. At $\sigma_{3}=100$ and $150 \mathrm{MPa}$ the instability started immediately after the peak strength and was extremely violent.

In all tests the variation of the axial specimen resistance (differential stress) with time was registered during the instability by the load cell adjacent to the specimen. An example of the variation of differential stress with time during the instability, and a fragment of this dependency, are shown in Figures $2 \mathrm{a}$ and $2 \mathrm{~b}$ for a confining stress of $\sigma_{3}$ $=75 \mathrm{MPa}$. Similar graphs for specimens tested at $\sigma_{3}=60,100$ and $150 \mathrm{MPa}$ are shown in Figures 1A, 2A and 3A in an Appendix. The specimen resistance at different stages of the instability is marked in the graphs for later discussion. Here $\Delta \sigma_{\min }$ is the minimal resistance just after fracture; $\Delta \sigma_{\mathrm{E}}$ is the resistance at the equilibrium conditions after the instability; $\Delta \sigma_{\text {res }}$ is the residual strength that was obtained after further deformation of the specimen in the static regime. The corresponding data for all specimens are shown in Table 1, which also gives the peak strength $\left(\Delta \sigma_{\max }\right)$ and the ratio $\Delta \sigma_{\text {res }} / \Delta \sigma_{\text {min }}$. It should be noted that, even though control of the test is lost during this immediate post-peak response, the stress data are still accurate owing to the close proximity of the load cell to the specimen and its relatively low inertia.

Figure 2 
Table 1 Key results from triaxial compression tests on dolerite

\begin{tabular}{|l|l|l|l|l|l|l|l|}
\hline$\sigma_{3}, \mathrm{MPa}$ & 0 & 10 & 30 & 60 & 75 & 100 & 150 \\
\hline$\Delta \sigma_{\max }, \mathrm{MPa}$ & 309 & 414 & 525 & 680 & 708 & 889 & 1220 \\
\hline$\Delta \sigma_{\min }, \mathrm{MPa}$ & & & & 38 & 64 & 111 & 72 \\
\hline$\Delta \sigma_{\mathrm{E}}, \mathrm{MPa}$ & & & & 150 & 173 & & 307 \\
\hline$\Delta \sigma_{\text {res }}, \mathrm{MPa}$ & & 110 & 140 & 220 & 280 & 360 & 450 \\
\hline$\Delta \sigma_{\text {res }} / \Delta \sigma_{\min }$ & & & & 5.8 & 4.4 & 3.2 & 6.2 \\
\hline
\end{tabular}

The following three features where observed in all tests: i) very low resistance $\Delta \sigma_{\min }$ (up to 6.2 times lower than normal residual strength provided by friction $\Delta \sigma_{\text {res }}$ ) immediately after the fracture development; ii) an intense shock wave at some stage of the fault displacement; iii) an increase in the specimen resistance after the shock wave. The shock wave was very significant in all tests, but especially at $\sigma_{3}=100 \mathrm{MPa}$, during which the load cell was destroyed (see Figure A2).

\section{Frictionless shearing mechanism after fracture}

The shear fracture propagation is associated with the development of two characteristic zones established experimentally using a combination of acoustic emission and petrographic methods [19, 20, 21]: i) a process zone that lies at the head of the fracture zone, where an echelon of microcracks develops oriented parallel to the maximum compressive stress direction; and ii) a core zone that forms immediately after the fault front has passed through. Existing models consider the mechanism of the fault displacement along the core zone as a buckling, rotation and failure of rock bridges (blocks) located between the tensile cracks [13-18]. The important feature of all these models is the proposition that the blocks maintain contact between each other providing corresponding friction. Figure 3 shows an early version of conventional frictional concepts of the fault movement with rotating blocks. According to these mechanisms, as the fault structure forms, the cohesive strength gradually decreases down to the minimum value, which is the residual strength determined by the friction law. More recent studies $[17,18]$ focusing on the development of the shear rupture also lead to a similar outcome as in Figure 3, with an echelon of blocks separated by tensile cracks.

Figure 3

In our model we propose that the blocks can lose contact between each other during rotation, creating voids (see Figure 4). Such behaviour can be realised in hard rocks failed at high confining pressure, due to i) high material strength and ii) suitable block size (length) providing the block stability (integrity). In this case the blocks can rotate without sliding along their surfaces, operating as hinges. Figure 4a shows a fragment of the core zone just after the fault front has passed through. Dotted arrows here illustrate the orientation of major and minor stresses adjacent to the fault structure. The resistance to further movement of the fault is determined by the behaviour of blocks located between 
the echelon of tensile cracks. For simplicity we assume that the resistance to rotation of these blocks in zones of contact with the fracture faces is negligible and the ratio (length of block/width of block) $r / w>1$.

Figure 4

Figure 4 shows four stages of the fault movement under the effect of shear force $F$ and normal load $N$. Distance $s$ between centres of rotation of the blocks stays constant at all stages. The diagrams presented in Figures $4 \mathrm{e}$ and $4 \mathrm{f}$ show how values of fault resistance $F^{\prime}$ may be calculated at different fault displacements, with $N^{\prime}$ being the normal reactive force, $r$ the block length, $h$ the initial (and final) fault thickness, $\alpha$ the angle of initial orientation of the tensile cracks (or block axis) to the fault direction, and $\beta$ the angle of the current orientation of the block axis to the fault direction. The range for the variation of angle $\beta$ is $\alpha \leq \beta \leq 180^{\circ}$ - $\alpha$.

The variation of the ratio $F^{\prime} / \mathrm{N}^{\prime}$ as a function of angle $\beta$ is given by

$$
\frac{F^{\prime}}{N^{\prime}}=\frac{1}{\tan \beta}
$$

The displacement $d$ along the fault, associated in this mechanism with block rotation, can be determined as follows with reference to Figure $4 \mathrm{f}$ for a fault of initial (and final) thickness $h$. A rotating block of length $r$ is shown in the initial and intermediate positions. This change of the block position is accompanied by fault displacement $d$ in the horizontal direction and can be expressed as:

$$
d=X_{\alpha}-X_{\beta}
$$

where

$$
X_{\alpha}=h / \tan \alpha
$$

and

$$
X_{\beta}=r \cos \beta
$$

The block length $r$ can be presented as:

$$
r=h / \sin \alpha
$$

Combining (3)-(5) in (2) we have:

$$
d=h\left(\frac{1}{\tan \alpha}-\frac{\cos \beta}{\sin \alpha}\right)=h K
$$

where $K$ is the displacement factor.

Figure 5 
Figure 5 presents the relation between the normalized fault resistance $\left(F^{\prime} / N^{\prime}\right)$ and the displacement factor $K$ obtained for a fault with initial orientation of the tensile cracks at $\alpha=30^{\circ}$ to the fault direction (as typically found for the dolerite specimens). A dotted line on the graph represents the level of the normalized resistance caused by a coefficient of friction of about 0.8 , as obtained for the dolerite specimens at residual strength. The graph shows that initially the fault resistance decreases with displacement, continuing past the residual frictional resistance (at point $\mathrm{M}$ ) and eventually reaching zero resistance at point $O$, where the angle $\beta=90^{\circ}$. In the extreme, zero resistance occurs between points $\mathrm{O}$ and $\mathrm{P}$, where $\beta$ reaches $180^{\circ}-\alpha$. When the blocks have completed their rotation at point $\mathrm{P}$, corresponding to Figure $4 \mathrm{~d}$, the resistance is restored sharply. The sharply increased fault resistance results from the sudden termination of 'free' rotation of the blocks; the impact associated with the rotation limit may lead to a significant shock wave. Any further fault displacement occurs by means of frictional shear accompanied by wear and attrition of sliding surfaces.

Three features observed for the dolerite specimens tested support the assumed mechanism that gives rise to near frictionless shearing immediately following fracture, namely: i) low resistance just after fracture; ii) the occurrence of a shock wave; and iii) the subsequent increase in the specimen resistance back to a residual frictional value.

\section{Method of post-peak curve restoration}

Controlling failure for specimens characterized by a positive post-peak modulus is a difficult task, which becomes impracticable for hard rocks tested at high confining pressure due their extremely brittle response. It should be emphasised that during such uncontrollable failure it is impossible to measure correctly the axial specimen deformation necessary to determine the post-peak branch of the stress-displacement curves. This is because the positive modulus requires corresponding unloading and axial 'extension' of the specimen instead of the continuing compression that takes place following failure as the elastic energy stored in the loading system is released. So, data obtained during this uncontrollable process is inevitably incomplete, preventing analysis of the immediate post-peak response. Our knowledge about hard rock behaviour during this stage is very poor, but below we propose a new method that has potential to restore the lost information in an approximate manner.

Assuming that the proposed 'block-rotation' frictionless mechanism did indeed occur in the tests at high confining stress, we can assume that points $\mathrm{M}, \mathrm{O}$ and $\mathrm{P}$ in Figures $2 \mathrm{~b}$, A1, A2 and A3 correspond to those on the graph in Figure 5. Using that graph, together with equation (6) and relevant experimental data, it is possible to restore the post-peak part of the stress-displacement curves for the specimens that showed uncontrollable brittle fracture. An example for the specimen tested at $\sigma_{3}=75 \mathrm{MPa}$ is shown in Figure 6, as explained below.

Figure 6

The thick line before point B here is the experimentally obtained curve. Point B on the graph is the start of the instability. The next point of the post-peak curve that can be determined with any validity corresponds to the stress level equal to the residual strength (point M). This is because fracture propagation will be complete by this point so that the 
structure of the whole fracture represents the core zone rather than the process zone. From Figure 5 the displacement factor, $\mathrm{K}$, is close to 0.5 at this value of residual strength.

For the tested specimen the value of residual strength is $\Delta \sigma_{\text {res }}=280 \mathrm{MPa}$ (a residual axial load of $280 \mathrm{kN}$ ). The fault thickness $h$ was measured after the test to be about 0.12 $\mathrm{mm}$. The actual value of fault displacement in the direction of the specimen axis $d^{\prime}=d$ $\cos 30^{\circ}$ for point $\mathrm{M}$ is therefore about $0.05 \mathrm{~mm}$ (see Equation 6). The displacement $d^{\prime}$ is the irreversible deformation and should be measured from the line of elastic unloading $\mathrm{AB}$ as shown in Figure 6. Point $\mathrm{N}$ corresponds to the stress level that is half of the residual strength $(140 \mathrm{kN})$. The value of displacement factor $\mathrm{K}$ at this point is about 1 and the corresponding value of $d^{\prime}=0.1 \mathrm{~mm}$. Points $\mathrm{O}$ and $\mathrm{P}$ represent the origin and the end of the resistance-less stage of the fault movement where the value of axial load should be equal to zero. Displacement factors for these points are 1.73 and 3.46. Corresponding values of irreversible displacement $d^{\prime}$ for these points are shown on the graph. After point $\mathrm{P}$ the fault resistance is determined by the restored friction, with a gradient that has been taken as parallel to the response RG actually measured in a supplementary static test once stability was recovered. The residual strength was determined also in the same test. Note that because of the dynamic nature of the failure, the measured equilibrium point at E lies below the residual strength, and to the right of the reconstructed response curve. Line BD on the graph characterises the stiffness of the loading system.

The beginning part (BM) of the plotted curve correlates well with the post-peak part of the curve obtained experimentally before point B. The curve obtained reflects the absence of shear resistance within some range of displacement just after the fault formation (we will call the fault resistance in this range the post-fracture resistance) and the subsequent re-loading process associated with the residual friction being recovered after point P. Shaded areas on the graph signify the energy absorbed during the relative displacement of the fault faces separated by rotating blocks. It should be mentioned that the upper part of the shaded area between points B and M should also include the energy absorbed by the fracture process associated with the creation of the echelon of tensile cracks between blocks. This form of energy has not been estimated in the present paper.

The minimum shear resistance $\Delta \sigma_{\min }$ obtained for the dolerite specimens is greater than zero. This is because the thickness of real faults is very irregular, and due to this the frictionless mechanism is activated in different fault zones at different stages of the fault displacement. Figure 7 illustrates this, showing an irregular fault before and after displacement. The relative displacement $d$ of fault faces in different fault zones is the same but the angle $\beta$ of the block orientation after rotation is different. In the thin part of the fault $\beta=90^{\circ}$ which corresponds to the shear resistance equal to zero. In the thicker fault zones the frictionless mechanism is still not activated. The thinner the fault zone the smaller is the displacement required to activate the frictionless mechanism. This will be discussed in further detail in section 8. Overall, though, despite the formation of a frictionless structure along the whole fault the non-simultaneity of the activation results in a minimum fault resistance greater than zero.

Figure 7 
The resulting post-peak curve reconstructed in Figure 6 differs remarkably from the form traditionally assumed, and explains a number of paradoxes observed in laboratory and field conditions, as discussed below.

\section{Low fault resistance}

The reconstructed graph shows that the range (OP) of the frictionless response for this specimen is located at the beginning of the shear displacement and is significantly smaller than the total fault displacement (AE) prior to regaining stability. This means that the initial fault structure corresponding to the frictionless stage will be completely destroyed by the end of the instability; this is the reason why the frictionless mechanism has not been detected in experiments until now. In spite of its high stiffness, the laboratory loading system is still too soft to allow the total displacement to be restricted to within the frictionless range. The softness results not just from the loading system but also from the specimen itself, which accumulates greater elastic energy before the start of instability than the loading system (comparing area $\mathrm{ABC}$ with $\mathrm{BCD}$ ). The only way to stop the total displacement within the range (OP) would be an artificial dynamic withdrawal of the excess energy from the 'specimen-loading system' assembly during the uncontrolled fracture process.

In natural conditions the situation in a deep-seated rock mass involving a shear fracture can be significantly stiffer than in the laboratory conditions, and can therefore arrest the instability within the range of the frictionless response. In this case the fault resistance for further displacement would be lower than it is dictated by the friction law, since it will lie somewhere along an equivalent path to OPF in Figure 6. The apparent low strength of existing major faults [7] can be explained by the realisation of the frictionless rotational mechanism within the structure of these faults. Since the width of the fault zone can be several hundred metres [22], significant shear displacement can occur with extremely low friction.

Figure 8

The fact that large scale shear fractures formed at great depth can involve elements of the frictionless mechanism can be illustrated by a set of photographs by Ortlepp [23] some of which are presented in Figure 8. These photographs show fragments of shear fractures that caused large rockbursts in a deep South African gold mine. The fractures occurred in quartzite at a depth of more than $2000 \mathrm{~m}$. Ortlepp points out that all of the shears in Figure 8 were found in highly stressed intact rock with no faults or, indeed, any other form of natural pre-existing discontinuities.

The damage zone of the fractures involves an echelon of blocks separated by tensile cracks. Faces of the fractures are sharply defined because rotation of the blocks is accompanied by fragmentation of them in the contact areas between the blocks and the fracture faces, which makes the contact areas distinctly visible. Angle $\beta$ of the block orientation in respect to the main fault direction is close to $90^{\circ}$. In accordance with the frictionless model, such orientation corresponds to very low (close to zero) shear resistance. While it is difficult to judge on this basis stability of the fault as a whole, due to the high irregularity of the fault structure, Ortlepp [23] points out that high seismic 
activity associated with the reactivation of existing faults is typical for the larger rockbursts in these deep gold mines.

\section{Abnormal fracture violence}

Another feature of the frictionless mechanism manifestation is the intense fracture violence, the reason for which can be explained using the graph in Figure 6. The total elastic energy stored within the 'specimen-loading system' assembly at point B before the instability corresponds to area ABD. The energy that determines the violence of a fracture process is the released energy. According to the graph in Figure 6 the released energy corresponds (approximately) to area BOPF. The conventional approach proposes that the minimum fault resistance is determined by the residual strength. In this case the released energy would correspond to area BMF. Comparing the two, it is clear that area $\mathrm{BOPF}$ is much greater than area BMF, which means that the frictionless mechanism activation intensifies the fracture violence. Abnormally intense violence of shear fracture events at high confining pressure (or great depth) has been observed in the laboratory and in field conditions as mentioned above.

\section{Increase in fracture violence with depth}

Analysis of shear fracture rockbursts and earthquakes shows that the intensity of these events has a tendency to increase with depth. This is borne out by the fact that shear rupture rockbursts are associated with deep mines only [24], and that large earthquakes are normally nucleated from great depth, typically 10 to $15 \mathrm{~km}$ [22, 25-27]. The results obtained on dolerite specimens show a similar trend of increasing violence of shear fracture with increasing confining pressure. A set of graphs corresponding to $\sigma_{3}$ of 30, 60, 75, 100 and $150 \mathrm{MPa}$ is shown in Figure 9. Post-peak curves of these graphs (except $\sigma_{3}=$ $30 \mathrm{MPa}$ ) were restored using the method discussed above. Black areas on the graphs correspond to the energy released from the tested specimens during the instability. The graphs demonstrate very significant increase in the released energy with rising confining pressure.

Figure 9

The most important feature of the results obtained is the discovery of the following paradoxical fact: in spite of the increase in rock strength $\left(\Delta \sigma_{\max }\right)$ and the amount of accumulated elastic energy with increasing confining pressure, the post-fracture resistance (prior to mobilisation of the residual frictional strength) stays low and practically constant $\left(\Delta \sigma_{\min }\right.$ in Table 1$)$. This imbalance in the rock properties is the main source of the phenomenon discussed above. No doubt that with further increase in depth, and thus of both confining pressure and temperature, the conditions necessary for the frictionless mechanism to operate are eventually eliminated and the rocks revert to ductile behaviour. What is the limiting depth for that? Presumably somewhere within or beyond the 10-15 km zone, but special experimental investigations are required to answer that question. 


\section{Increasing brittleness of rock with depth}

The increase in brittleness with increase in confining pressure obtained on dolerite specimens is a further paradoxical feature of hard rocks. What is the reason for this increasing brittleness? Two different mechanisms explain this phenomenon at different levels of confining pressure.

The first mechanism operates at low confining pressure and is associated with the change in fracture mode. At $\sigma_{3}=0$ and $10 \mathrm{MPa}$ specimens failed with the formation of a number of long tensile cracks as illustrated in Figure 1. At higher confining pressures starting from $\sigma_{3}=30 \mathrm{MPa}$ the failure mode changes to one with a shear plane inclined at an angle $\alpha$ of $25^{\circ}-30^{\circ}$ to the specimen axis. The first fracture mode is more powerconsuming compared with the second one. So, the gradual transition from one fracture mode to the other is accompanied by increasing instability of the failure process as a whole. This form of increasing brittleness can be exhibited by very different types of rock including very weak (e.g. lignite) and hard rocks (e.g. granite) [1, 28, 29].

The second mechanism responsible for increasing brittleness is mainly relevant for hard rocks, involves a single fracture mode and is associated with the reduction in shear fracture energy with increase in confining pressure. The mechanism of this phenomenon is still not understood but below we propose a possible version of it.

The fact that the frictionless mechanism was activated in all dolerite specimens failed under high confining pressures suggests that the increasing brittleness is caused by some feature of the frictionless mechanism. It is known that an increase in confining pressure leads to a decrease in the length of tensile cracks developed in the material body, including within the fault zone. The crack length determines the length $r$ of rotating blocks and, consequently, the fault thickness $h=r \sin \alpha$. The fault thickness measured for the dolerite specimen tested at $\sigma_{3}=75 \mathrm{MPa}$ was about $0.1 \mathrm{~mm}$. To illustrate the influence of the block length on the post-peak response let us construct the post-peak part of the stress-displacement curves for the same specimen at three different levels of the fault thickness: $h=0.3,0.1$ and $0.033 \mathrm{~mm}$. The graphs obtained are shown in Figure 10, where the shaded areas correspond to the energy absorbed by the fractures at displacements up to point $\mathrm{O}$, which is the start of zero resistance.

Figure 10

These graphs show clearly the essence of the increasing brittleness, which results from a shortening of the rotating blocks involved in the frictionless shear mechanism due to the rising confining pressure. The shorter are the blocks, the less displacement is required to provide the same strength degradation and, consequently, the less power consuming is this process.

The discovered phenomenon of hard rock embrittlement with increase in confining pressure can be proposed as a reason for the increase in earthquake and shear rupture rockburst activity with depth. Due to the frictionless mechanism, high confining pressure paradoxically changes the rock properties making rocks increasingly brittle. The more brittle is the rock behaviour the more likely is the loss of stability due to failure. Increasing brittleness with confining stress takes place up to some depth where rising pressure and temperature with depth start to suppress the frictionless mechanism operation. 


\section{Critical minor stress and operative range for the frictionless mechanism}

Let us compare the constructed graphs in Figure 10 with the experimental curves in Figure 1 . The shape of the curve obtained at $\sigma_{3}=30 \mathrm{MPa}$ is similar to the graph for $\mathrm{h}=$ 0.3. In the real situation, however, the resistance of the fault did not decrease below the residual frictional strength. This fact can be explained as follows. Under these conditions, the relatively long blocks could not maintain their integrity during rotation, but were destroyed and thus eliminated any frictionless displacement. This means that the confining pressure of $30 \mathrm{MPa}$ is too low to activate the frictionless mechanism. Starting from $\sigma_{3}=60 \mathrm{MPa}$ the fault structure formed from shorter blocks became sufficient to operate as a series of hinges, thus providing frictionless fault resistance. Thus we can conclude that there is some minimum critical level of confining pressure (or minor stress) at which the frictionless mechanism can be activated in a particular hard rock and then applies over a 5 to 10 -fold operative range of confining pressure.

The results obtained give ground to assume that the location of an upper cutoff in seismicity at relatively significant depth is determined by the fact that at this depth the minor stress reaches the critical level at which the frictionless mechanism is activated. Below this critical depth the mechanism is applicable within some range of depth until high pressure and temperature suppress it. The operative range of depth where the frictionless mechanism is applicable may coincide with the unstable zone determined for earthquakes [22].

Restriction of shear rupture rockbursts to deep mines only has the same explanation. Using the frictionless concept it is also possible to explain another very interesting phenomenon observed in deep mines. Ortlepp [30] pointed out that shear rupture rockbursts nucleate in pristine rocks within the rock space at a point some considerable distance away from the surface of an opening, unlike other types of rockbursts (e.g. strain-burst, buckling, face crush) which occur right at the surface. Figure 11 illustrates the possible situation around an opening taking into account the frictionless concept.

Figure 11

The opening is located below the critical depth. The graph shown at the top of the figure characterises the distribution of the minor stress $\sigma_{3}$ around the opening. A range of minor stress located above the critical stress represents an operative range of stress where the frictionless mechanism is applicable. A graph at the bottom of the figure symbolizes the distribution of the differential stress $\Delta \sigma_{1}$ near the opening. A maximum of the $\Delta \sigma_{1}$ stress concentration is located at some distance from the open surface.

In the rock mass surrounding the opening, two zones of different rock behavior can be distinguished. Zone 1 is characterized by the level of minor stress being below the operative range. Rocks in these zones exhibit normal (well known) behavior. A possible relation between the post-peak rock stiffness and loading stiffness for this zone is illustrated by a graph on the left of the figure, which characterises the situation in this 
zone as stable. The situation in zone 2, by contrast, is abnormal and unstable despite the fact that the loading stiffness here is the same. Rocks in this zone have extreme brittleness due to the frictionless mechanism. A new fracture can be initiated at any point within this zone where the level of shear stress, caused by the stress concentration, exceeds the rock strength. The rupture development will be violent. The direction, attitude and extent of this rupture are determined by the prevailing stress field. It should be noted that to create the high stress concentration necessary for the fracture development a large scale abnormality in the crust is required. This may be in the form of a large scale mine or a pre-existing natural fault.

\section{Conclusions}

Modern earthquake seismology considers the development of faults in the earth crust, independently of their size, depth or sequence of formation (e.g. foreshock, mainshock and aftershock), as a process taking place in a significantly fractured crustal structure where strength and behaviour of rock is determined by a friction law [22, 31, 32]. It is considered that the crust is riddled with small faults of varying orientations, the reactivation of which depends on the stress level and a proper orientation of these faults.

This approach to the fault process bypasses a key question that is still unclear, regarding what mechanism can provide shear fracture development in pristine hard rocks at great depth. The importance of this question is based on the fact that all existing faults in the crust were initially formed in pristine rocks, the strength of which was significantly higher than their frictional strength. It is possible to suppose also that the development of new faults in pristine rocks within the crust takes place nowadays, and indeed experience in deep mining confirms this. The results discussed here have elucidated the mechanism of shear fracture development in pristine rocks.

The proposed frictionless mechanism explains a number of abnormal features observed in the fracture behaviour at high confining pressures. This mechanism provides low post-fracture resistance; abnormally high brittleness and intense fracture violence; and explains the increase in fracture violence and brittleness with rising confining pressure. The mechanism is activated only at a relatively high critical level of confining pressure and then applies over a 5 to 10-fold operative range of confining pressure.

Both rockbursts and earthquakes share a number of very similar features:

i) It is known that shear rupture rockbursts are associated with deep mines only and earthquakes take place below some depth, which is referred to as the upper stability transition. The important point is that shear rupture rockbursts nucleate in pristine rocks within the rock space at a point some considerable distance away from the open surface. These facts can be treated as evidence that shear fracture in hard rocks at triaxial compression can only develop at conditions where the minimum principal stress reaches (or exceeds) some critical level at which the rocks acquire some specific quality. We propose that this specific quality is the capability to form the frictionless rotational shearing structure.

ii) It is known also that the zone of earthquake activity (the unstable zone) is located within some depth range between two boundaries: the upper and lower stability transition. Furthermore, the activity and intensity of earthquakes increases with 
depth and the largest earthquakes nucleate mostly at great depth, close to the lower boundary. These facts are also in accordance with the frictionless concept.

iii) Finally the apparent low shearing resistance of major faults can also be treated as a manifestation of the frictionless mechanism.

On the basis of the results obtained and subsequent analysis we can hypothesise that in the earth's crust spontaneous shear fracture development in pristine hard rocks is governed by a frictionless mechanism involving free rotation of hinged blocks separated by fractures. The unstable zone in this case coincides with the operative zone for the frictionless rotational mechanism.

\section{Appendix}

Figure 1A

Figure 2A

Figure $3 \mathrm{~A}$

\section{References}

1. Tarasov, B.G. and Dyskin, A.V. The phenomenon of anomalous rock embrittlement. Sixth International Symposium on Rockburst and Seismicity in Mines Proceedings, Australia, 311-317 (2005).

2. Ortlepp, W.D., Armstrong, R., Ryder, J.A. and O’Connor, D. Fundamental study of micro-fracturing on the slip surface of mine-induced dynamic brittle shear zones. Sixth International Symposium on Rockburst and Seismicity in Mines Proceedings, Australia, 229-237 (2005).

3. McKenzie, D. and Brune, N. Melting on fault planes during large earthquakes. Geophys. J. R. astr. Soc., 29, 65-78 (1972).

4. Sibson, R.H. Power dissipation and stress levels on faults in the upper crust. $J$. Geophys. Res. 85, 6239-6247 (1980).

5. Chester, F.M., Evans, J.P. and Biegel, R.L. Internal structure and weakening mechanisms of the San Andreas Fault. J. Geophys. Res. 98, 771-786 (1993).

6. Di Toro, G., Goldsby. D.L. and Tullis, T.E. Friction falls towards zero in quartz rock as slip velocity approaches seismic rates. Nature, 427, 436-439 (2004).

7. Hickman, S.H. Stress in the lithosphere and the strength of active faults. Rev. Geophys. 29,759-775 (1991).

8. Stesky, R., Brace, W., Riley, D. and Robin, P-Y. Friction in faulted rock at high temperature and pressure. Tectonophys. 23, 177-203 (1974).

9. Byerlee, J. D. Friction of rocks. Pure Appl. Geophys. 116, 615-626 (1978).

10. Dieterich, J. H. Time dependent friction and the mechanics of stick slip. Pure Appl. Geophys. 116, 790-806 (1978)..

11. Blanpied, M. L., Lockner, D. A., and Byerlee, J. D. Frictional slip of granite at hydrothermal conditions. J. Geophys. Res. - Solid Earth. 100, 13045-13064 (1995).

12. Tsutsumi, A and Shimamoto, T. High-velocity frictional properties of gabbro. Geophys. Res. Lett. 24,699-702 (1997). 
13. Peng, S. and Johnson, A.M. Crack growth and faulting in cylindrical specimens of Chelmsford granite. Int. J. Rock Mech. Min. Sci. 9, 37-86 (1972).

14. Horii, H., and Nemat-Nasser, S. Compression-induced microcrack growth in brittle solids: Axial splitting and shear failure, J. Geophys. Res., 90, 3105-3125 (1985).

15. Cox, S.J.D. and Scholz, C.H. On the formation and growth of faults: an experimental study. J. Struct. Geol., 10, 413-430 (1988).

16. Ashby, M.F. and Sammis, C.G. The damage mechanics of brittle solids in compression, Pure Appl. Geophys., 133, 489-521 (1990).

17. Reches, Z. and Lockner, D., A. Nucleation and growth of faults in brittle rocks. $J$. Geophys. Res. Vol. 99, No. B9, 18159-18173 (1994).

18. Mandel, G. Faulting in brittle rocks. Springer-Verlag Berlin Heidelberg (2000).

19. Lockner, D.A., Byerlee, J.D., Kuksenko, V., Ponomarev, A. and Sidorin, A. Quasistatic fault growth and shear fracture energy in granite. Nature, 350, 39-42 (1991).

20. Lockner, D.A., Byerlee, J.D., Kuksenko, V., Ponomarev, A. and Sidorin, A. Observations of quasistatic fault growth from acoustic emissions. In Fault mechanics and transport properties of rocks (ed. B. Evans and T-F. Wong). Academic press, San Diego (1992).

21. Lei, X., Kusunose, K., Rao, M.V.M.S., Nishizawa, O. and Latoh, T. Quasi-static fault growth and cracking in homogeneous brittle rock under triaxial compression using acoustic emission monitoring. J. Geophys. Res. 105, 6127-6139 (2000).

22. Scholz, C. H. The mechanics of earthquakes and faulting. Cambridge University Press (2002).

23. Ortlepp, W., D. Rock fracture and rockbursts. The South African Institute of mining and metallurgy. Johannesburg (1997).

24. Ortlepp, W.D. and Stacey, T.R. Rockburst mechanisms in tunnels and shafts. Tunnelling and underground space technology. 9, 357-362(1994).

25. Macelwane, J. Problems and progress on the geologico-seismological frontier. Science, 83, 193-198 (1936).

26. Sibson, R.H.. Fault zone models, heat flow, and the depth distribution of earthquakes in the continental crust of the United States. Bull. Seismol. Soc. Am. 72, 151-163 (1982).

27. Das, S. and Scholz, C.H. Why large earthquakes do not nucleate at shallow depths. Nature 305, 621-623 (1983).

28. Santarelli, F.T. and Brown, E.T. Failure of three sedimentary rocks in triaxial and hollow cylinder compression test. Int. J. Rock Mech. Min. Si. \& Geomech. Abstr. 26, 401-413 (1989).

29. Stavrogin, A.N. and Tarasov, B.G. Experimental physics and rock mechanics. Balkema, India (2001).

30. Ortlepp, W. D. (2000). Observation of mining-induced faults in an intact rock mass at depth. Int. J. Rock Mech. Min. Si., 37, 423-436.

31. Nur, A. Nonuniform friction as a basis for earthquake mechanics. Pageoph 116,964-989 (1978).

32. Tse, S. and Rice, J. Crustal earthquake instability in relation to the depth variation of frictional slip properties. J. Geophys. Res. 91, 9452-9472 (1986). 


\section{Figure Captions}

Figure 1. Stress-strain curves and the fracture mode for dolerite specimens tested at different confining pressures.

Figure 2. Curves of differential stress versus time for dolerite specimen failed at confining pressure of $75 \mathrm{MPa}$.

a) - Total curve; b) - Fragment of the curve.

Figure 3. Concept of the frictional fault displacement (Peng and Johnson, 1972).

Figure 4. Idealized concept of the frictionless fault displacement in hard rocks.

Figure 5. Normalized fault resistance $F^{\prime} / N^{\prime}$ versus displacement factor $K$.

Figure 6. Complete load-displacement curve reconstructed for dolerite specimen tested at confining pressure of $75 \mathrm{MPa}$.

Figure 7. Features of the fault structure behavior in irregular faults.

Figure 8. Shear fractures involving elements of the frictionless mechanism (Ortlepp, 1997).

Figure 9. Elastic energy released from dolerite specimens at uncontrollable fracture under different confining pressures.

Figure 10. Complete stress-displacement curves plotted for three levels of the fault thickness $h$.

Figure 11. Zone of embrittlement and advanced violence caused by an opening (modified from Tarasov and Dyskin, 2005).

Figure 1A. Curves of differential stress versus time for specimen failed at confining pressure $60 \mathrm{MPa}$.

a) - Total curve; b) - Fragment of the curve.

Figure 2A. Curves of differential stress versus time for specimen failed at confining pressure $100 \mathrm{MPa}$.

a) - Total curve; b) - Fragment of the curve.

Figure 3A. Curves of differential stress versus time for specimen failed at confining pressure $150 \mathrm{MPa}$.

a) - Total curve; b) - Fragment of the curve. 


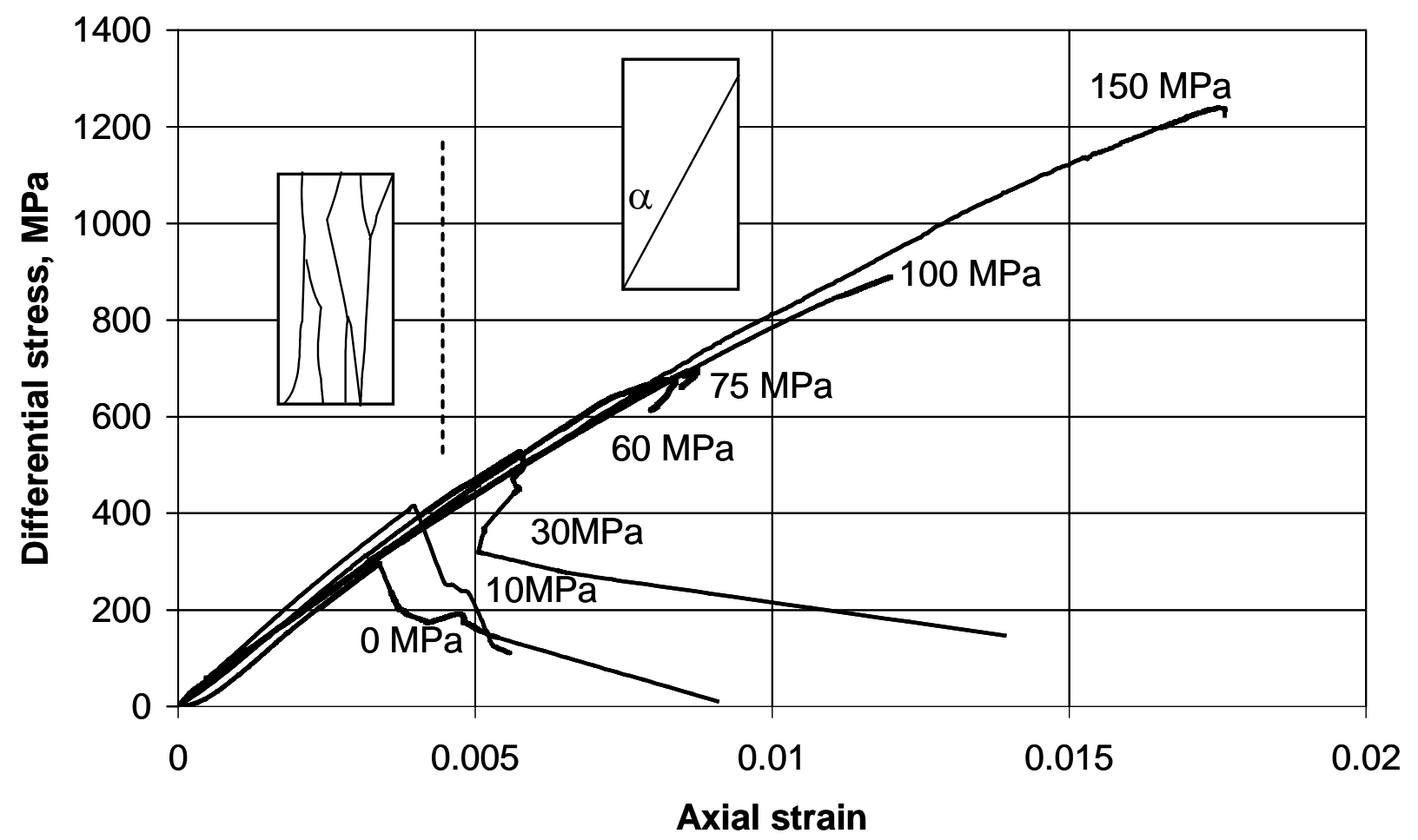

Figure 1. Stress-strain curves and the fracture mode for dolerite specimens tested at different confining pressures 


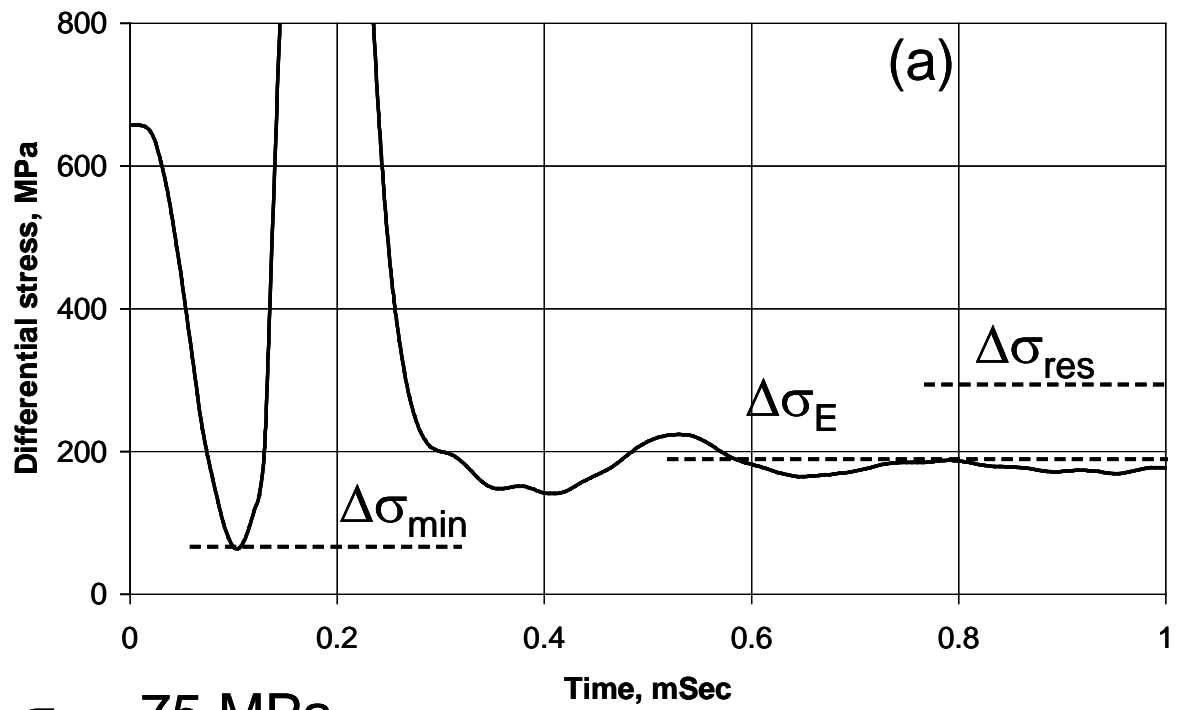

$\sigma_{3}=75 \mathrm{MPa}$

Time, $\mathrm{mSec}$

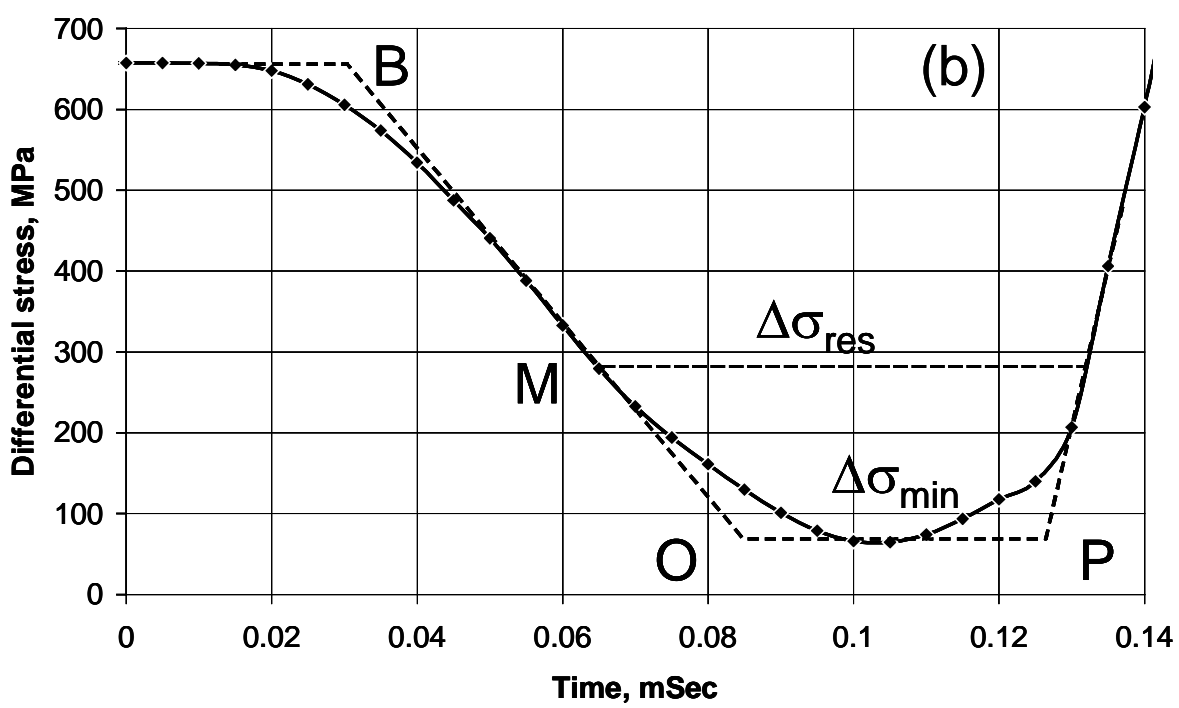

Figure 2. Curves of differential stress versus time for dolerite specimen failed at confining pressure of $75 \mathrm{MPa}$.

a) - Total curve; b) - Fragment of the curve 

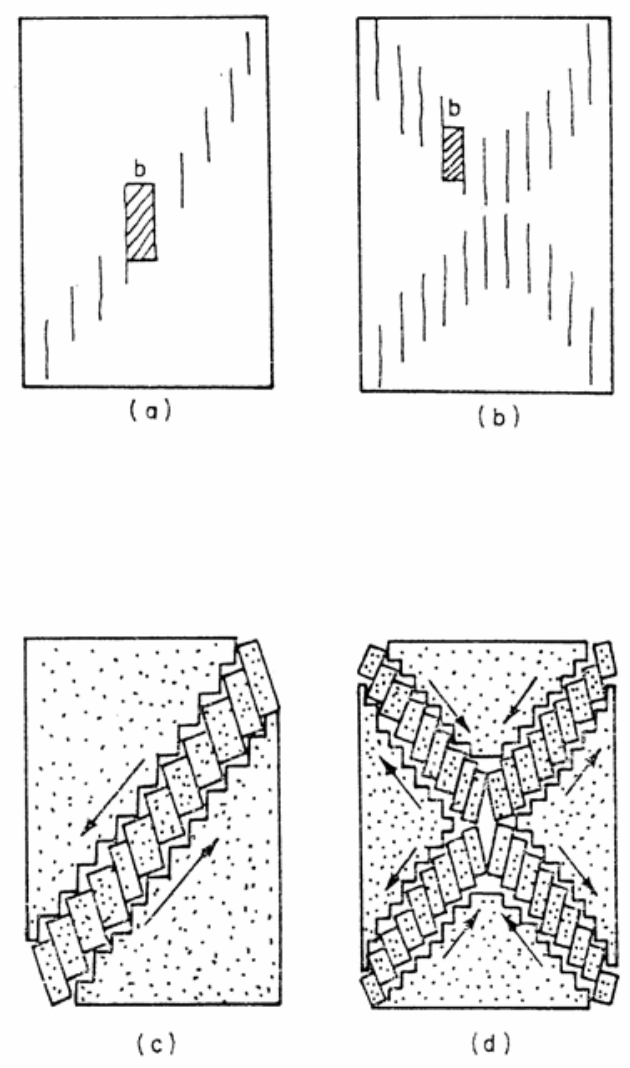

Figure 3. Concept of the frictional fault displacement (From Peng and Johnson, 1972) 
(a)
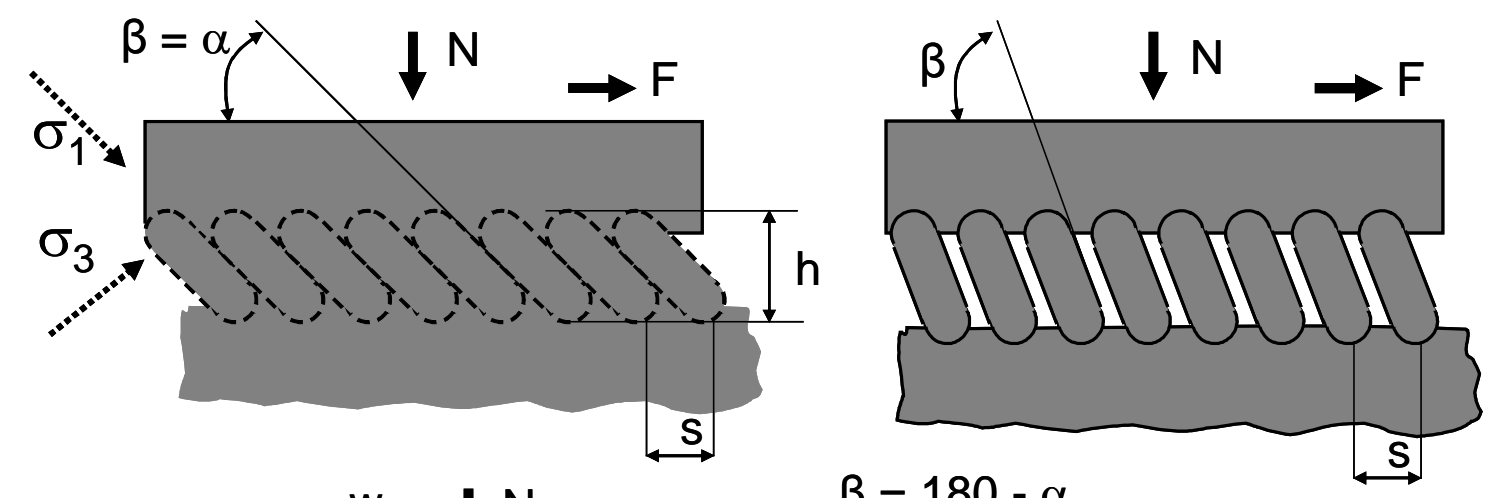

(b)

(c)
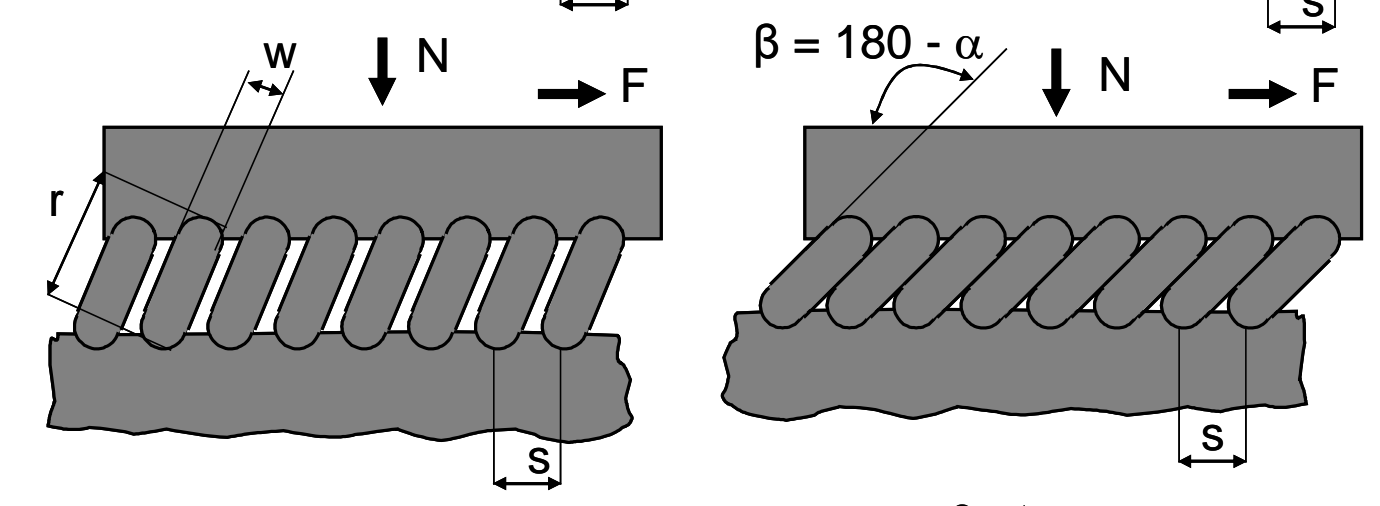

(d)

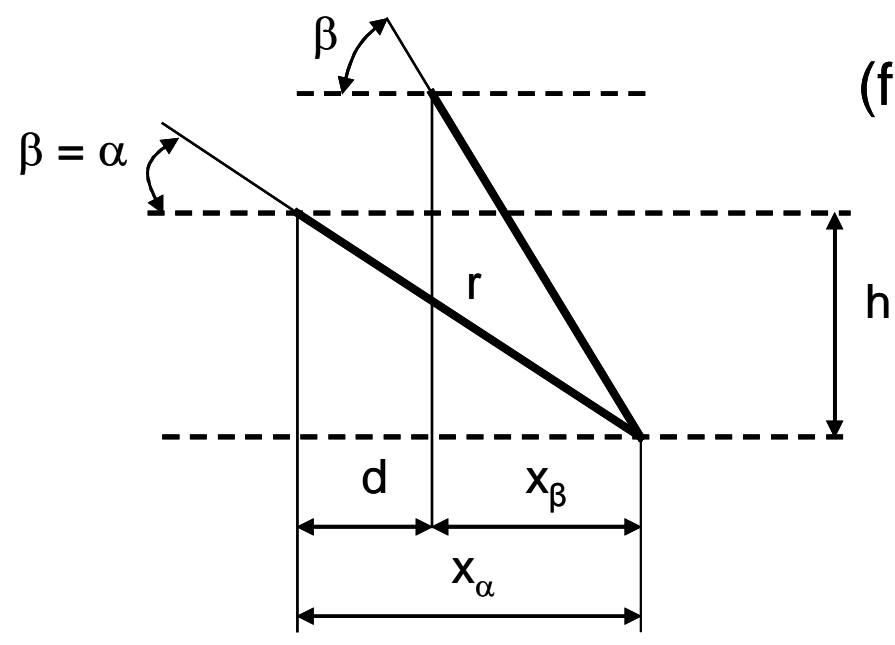

Figure 4. Idealized concept of the frictionless fault displacement in hard rocks 


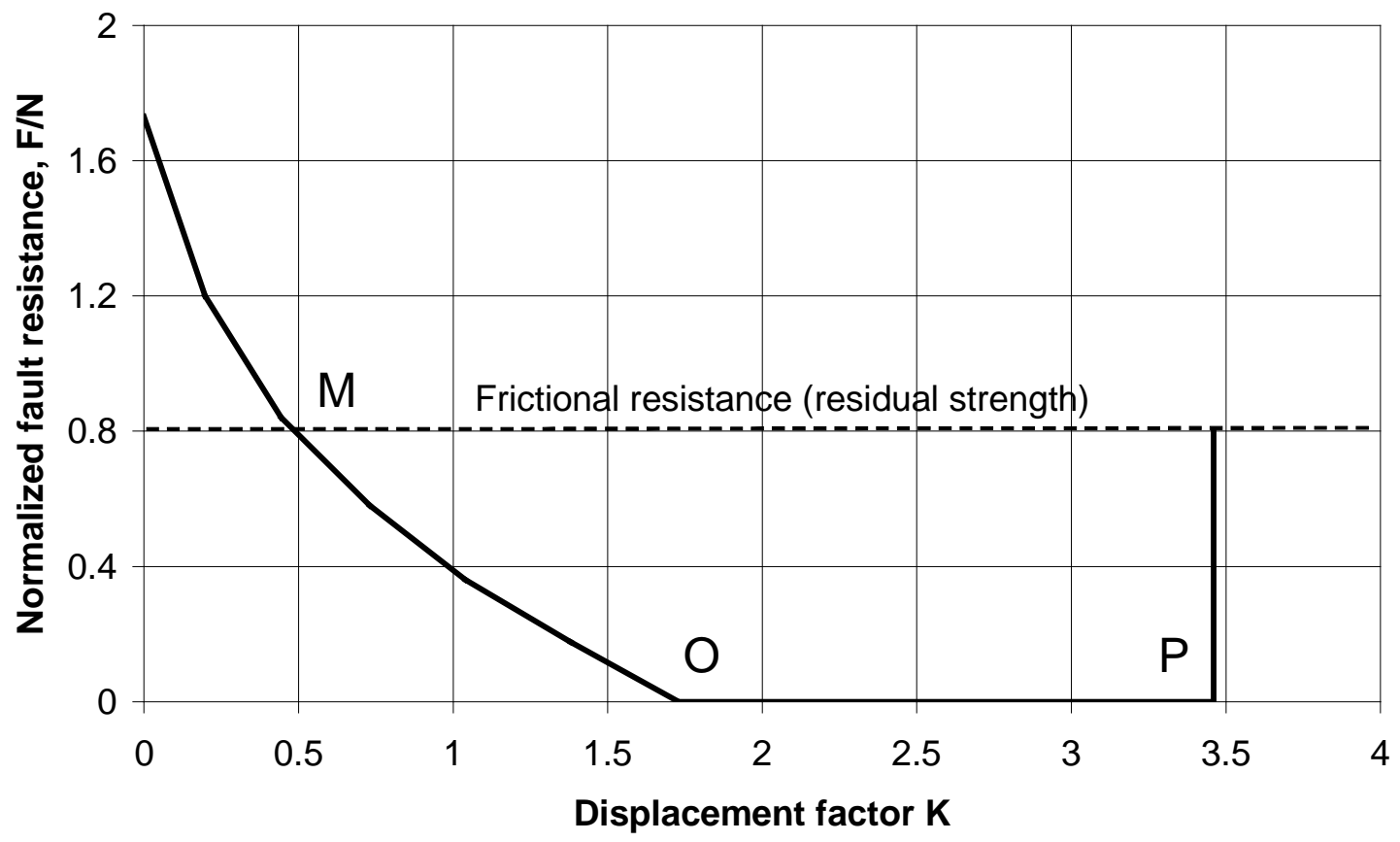

Figure 5. Normalized fault resistance $\mathrm{F}^{\prime} / \mathrm{N}^{\prime}$ versus displacement factor $\mathrm{K}$ 


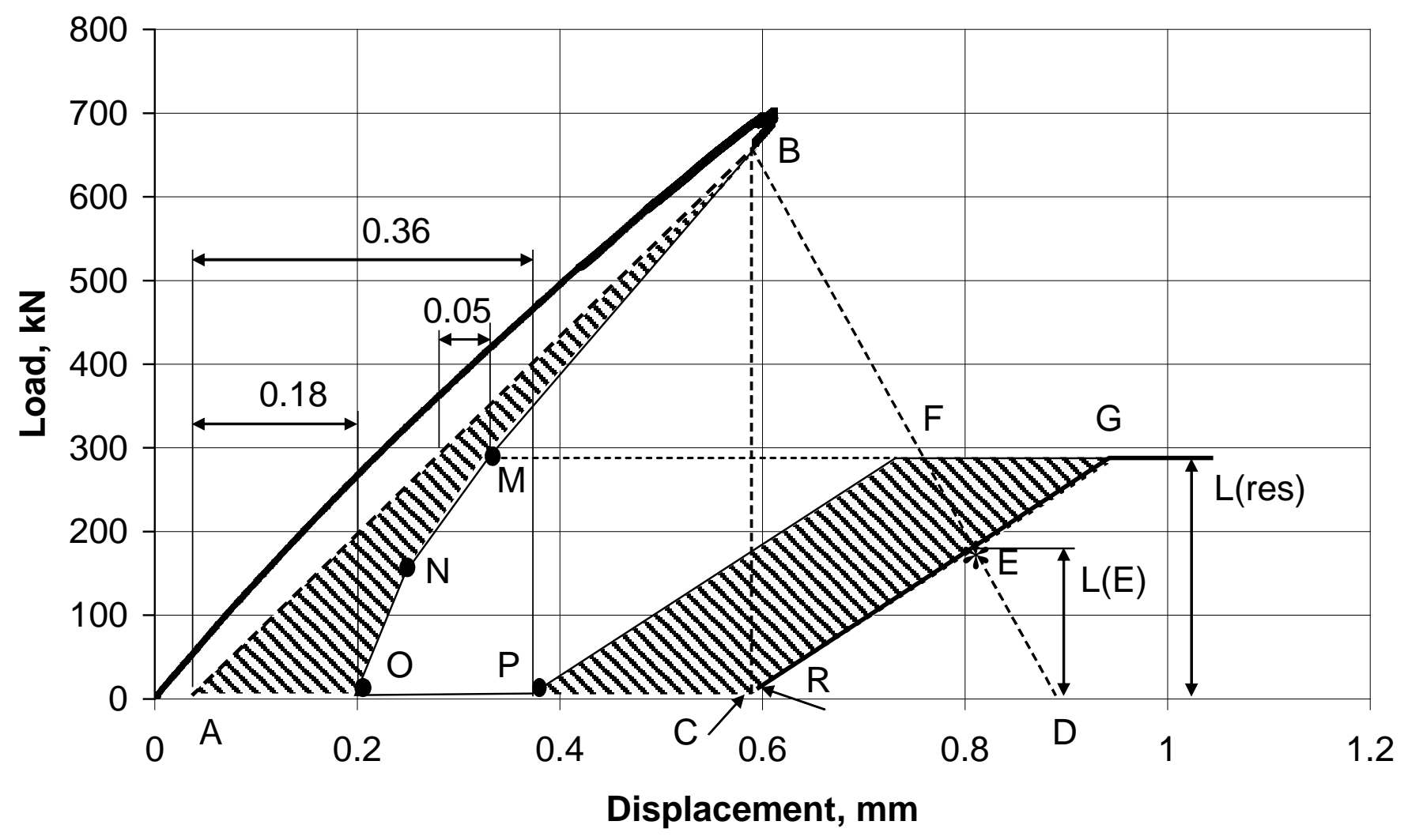

Figure 6. Complete load-displacement curve reconstructed for dolerite specimen tested at confining pressure of $75 \mathrm{MPa}$ 


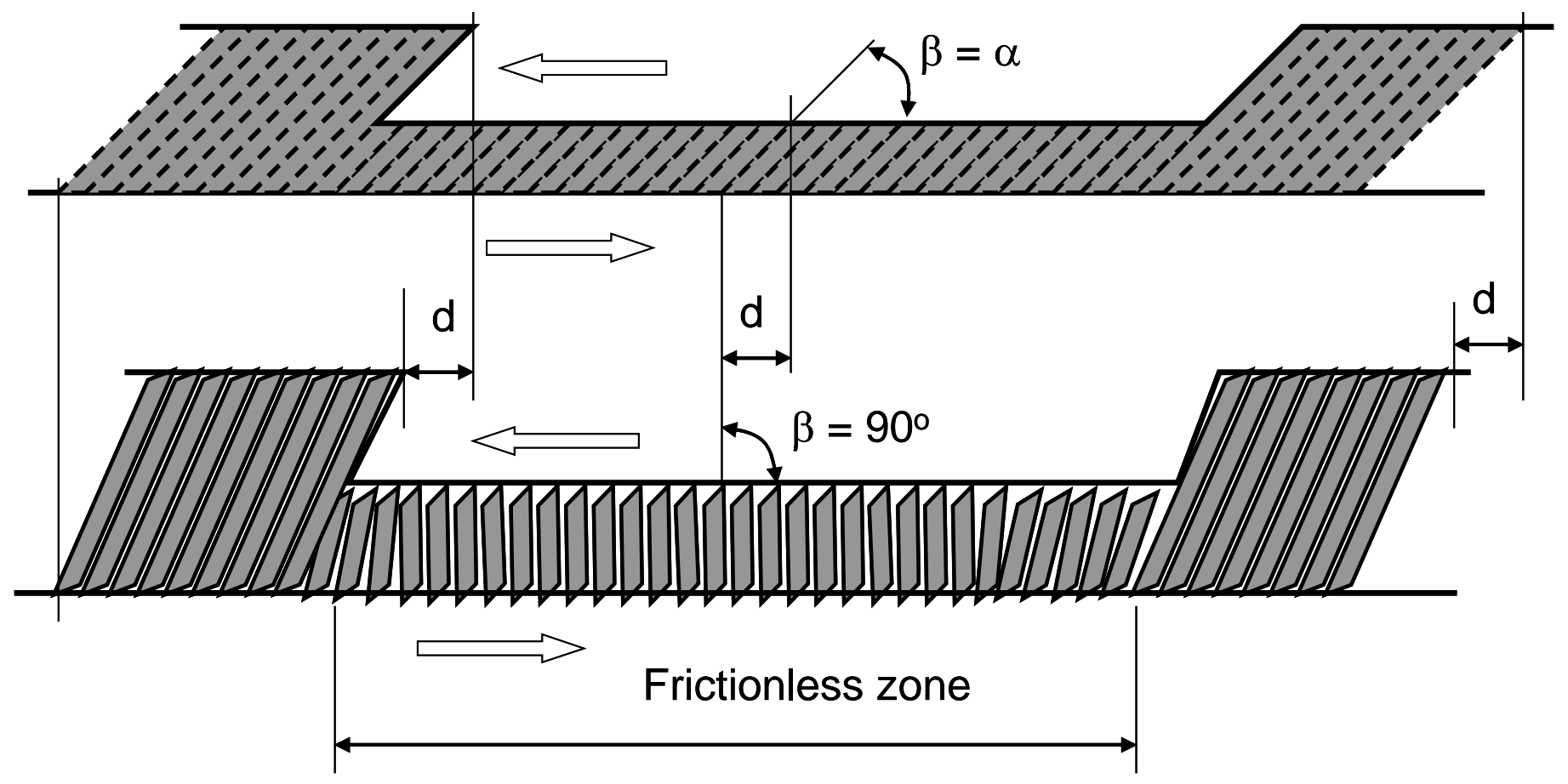

Figure 7. Features of the fault structure behavior in irregular faults 
$30 \mathrm{MPa}$
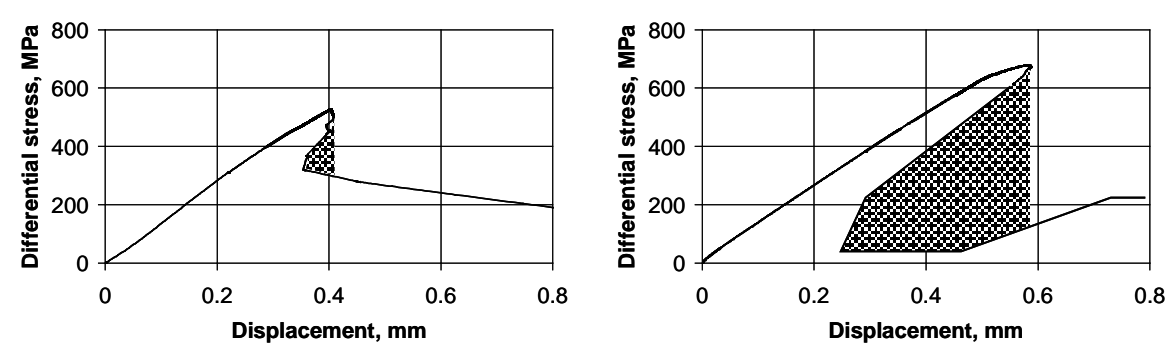

$75 \mathrm{MPa}$

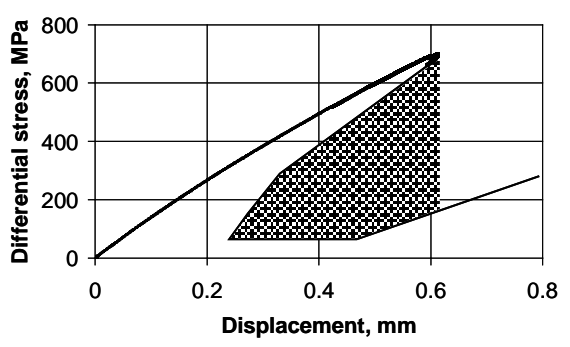

$150 \mathrm{MPa}$

\section{$100 \mathrm{MPa}$}
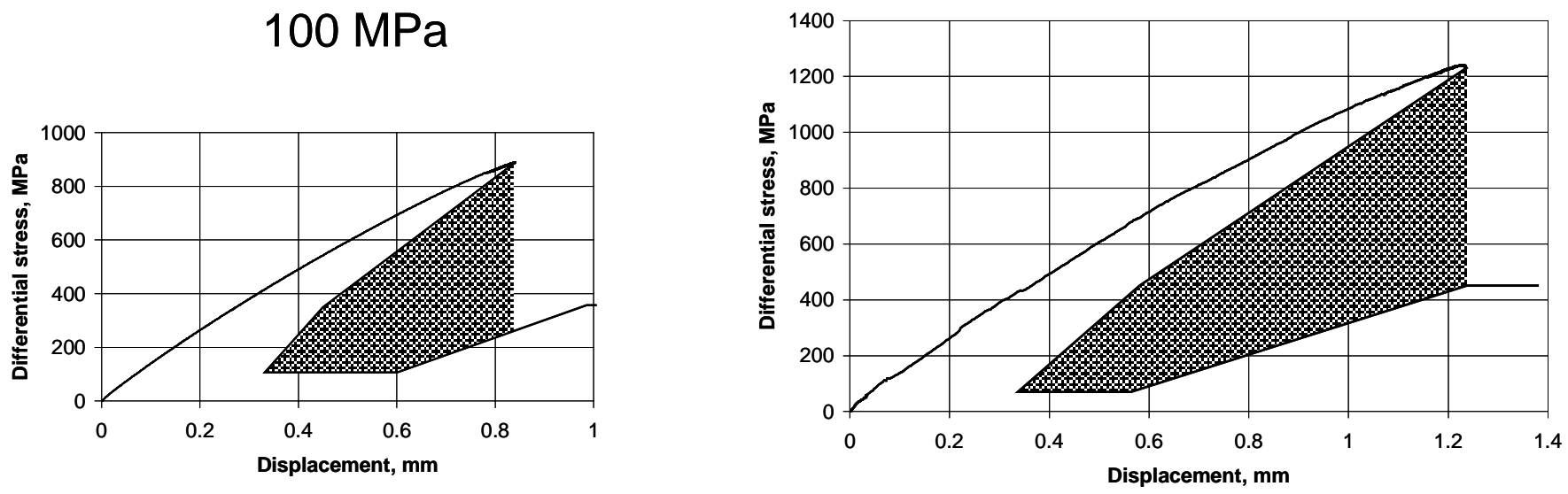

Figure 9. Elastic energy released from dolerite specimens at uncontrollable fracture under different confining pressures 

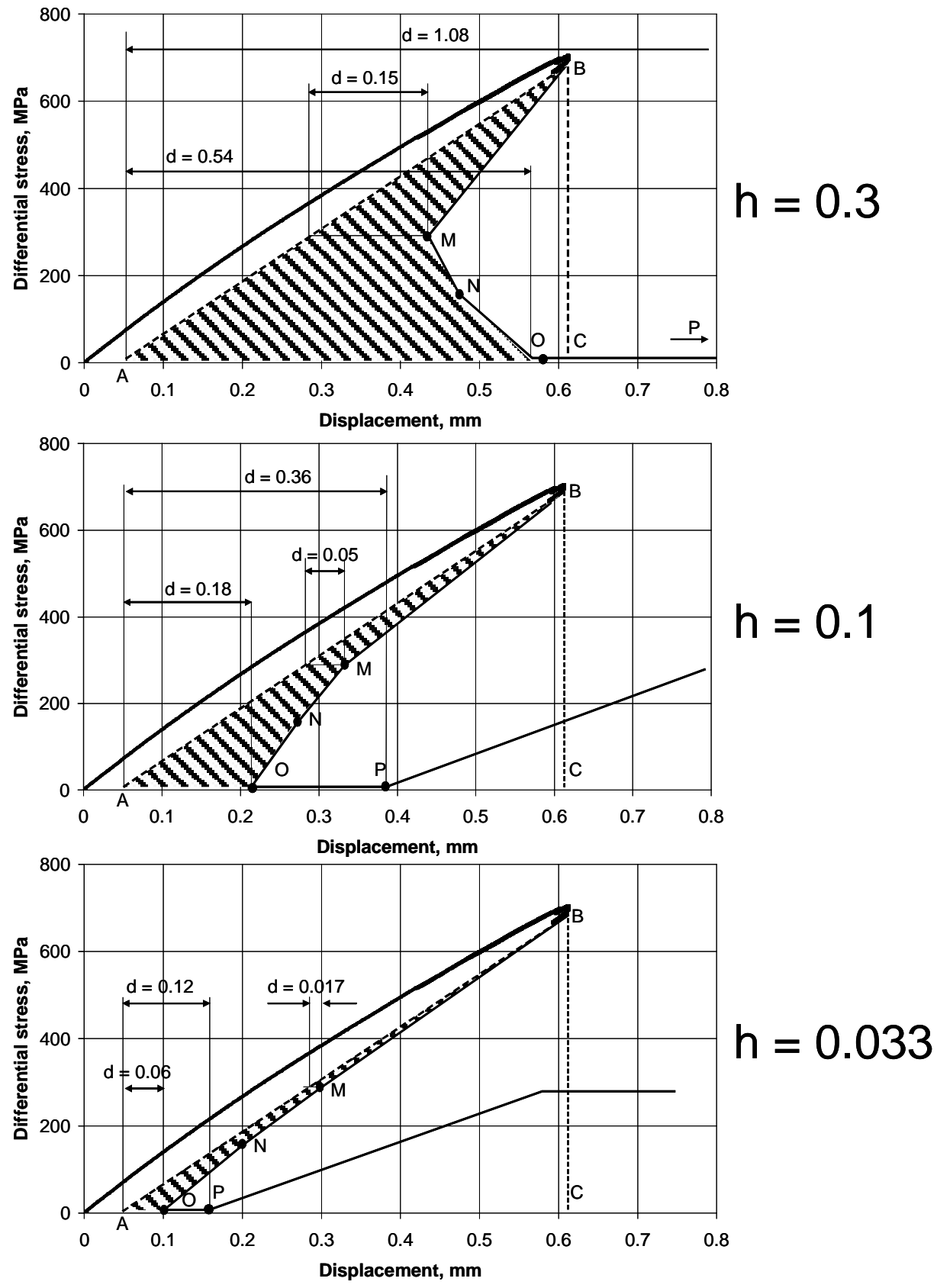

Figure 10. Complete stress-displacement curves plotted for three levels of the fault thickness $h$. 


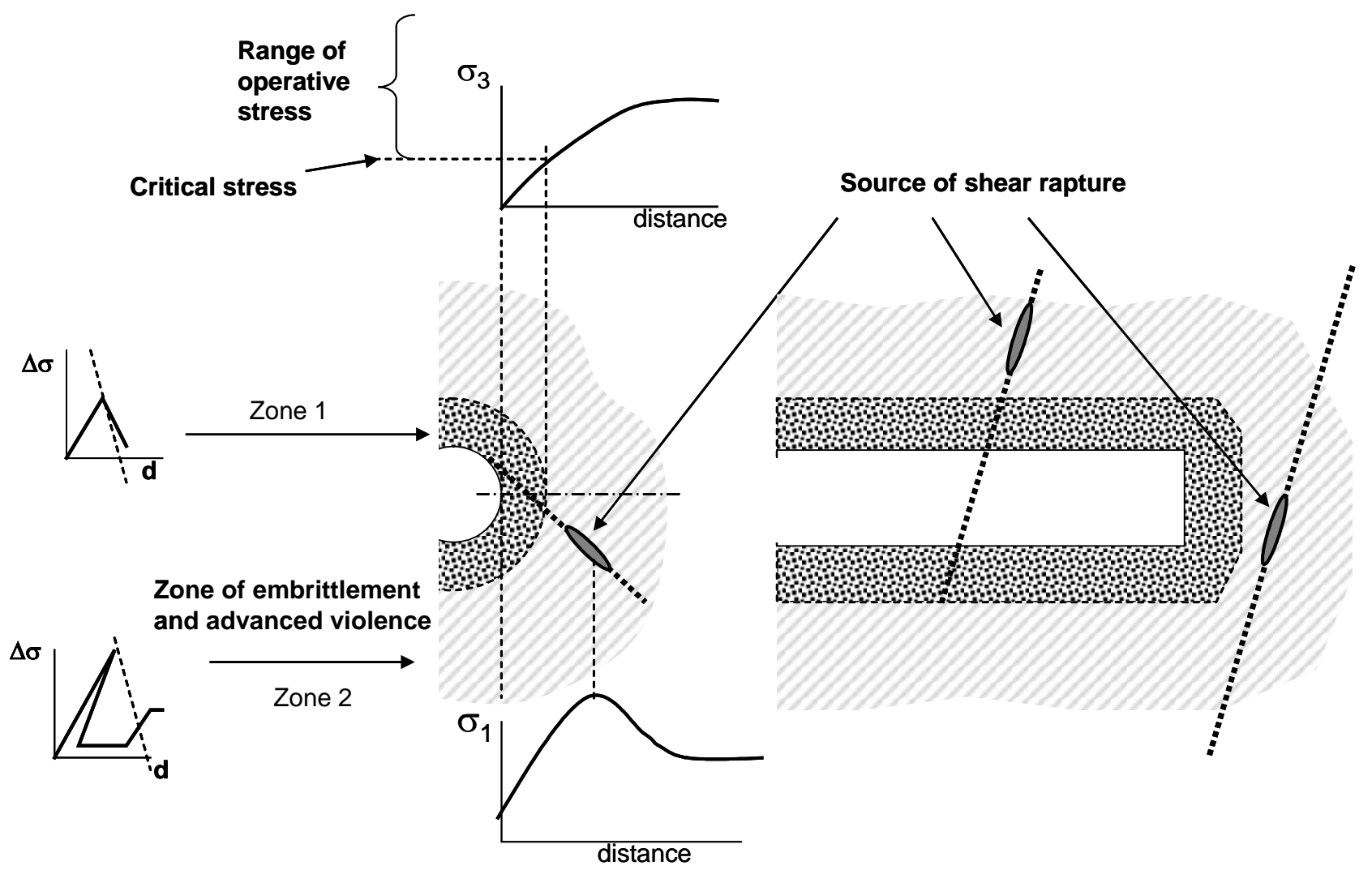

Figure 11. Zone of embrittlement and advanced violence caused by an opening (modified figure from Tarasov and Dyskin, 2005) 
a)

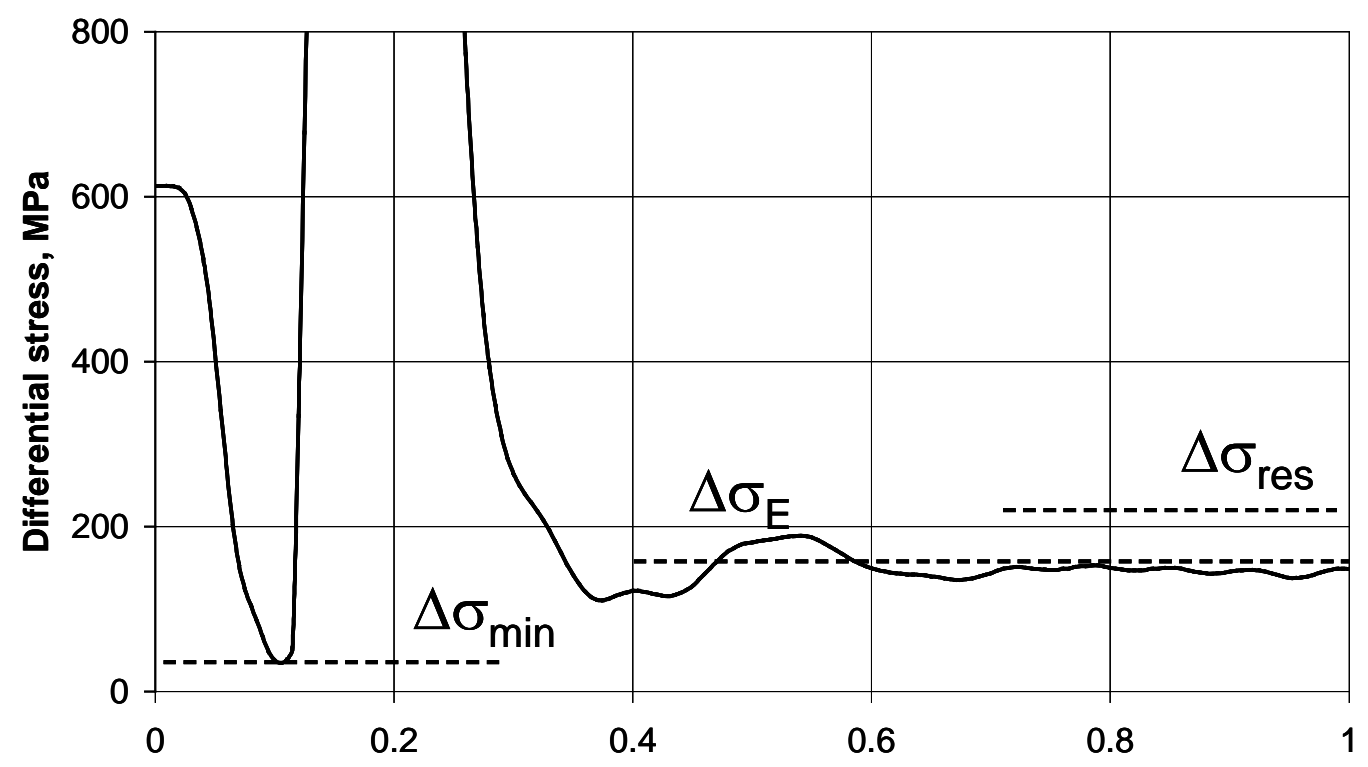

$\sigma_{3}=60 \mathrm{MPa}$

Time, $\mathrm{mSec}$

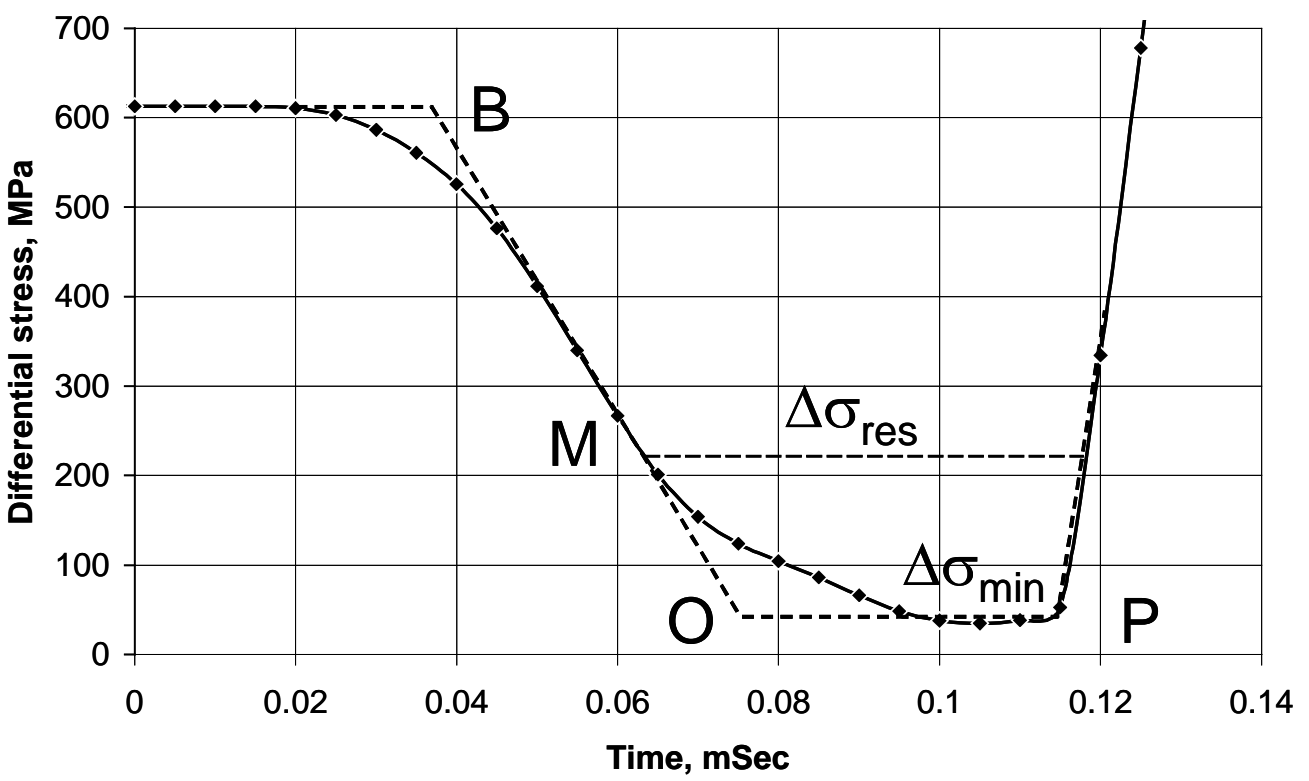

Figure 1A. Curves of differential stress versus time for specimen failed at confining pressure $60 \mathrm{MPa}$.

a) - Total curve; b) - Fragment of the curve 


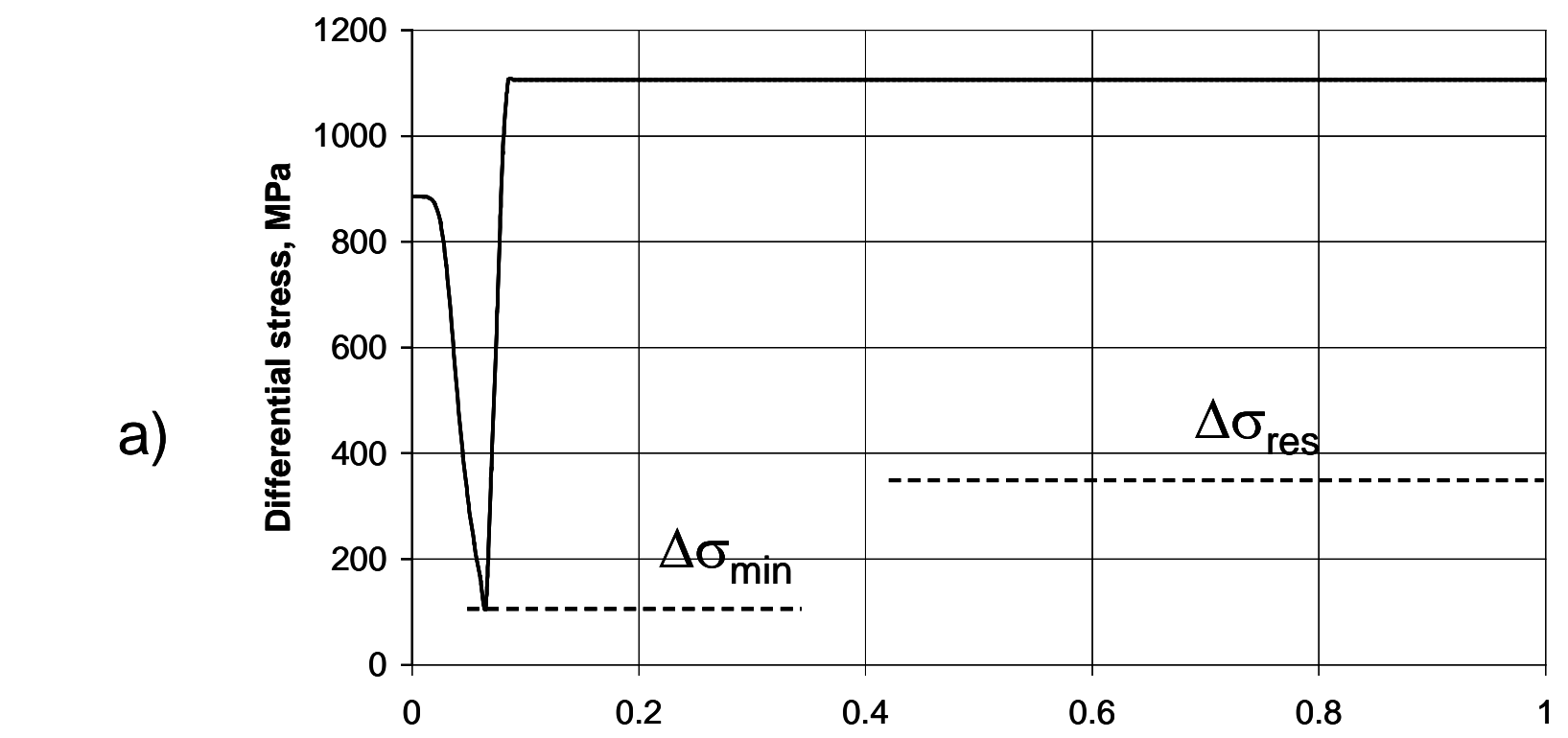

$\sigma_{3}=100 \mathrm{MPa}$

Time, $\mathrm{mSec}$

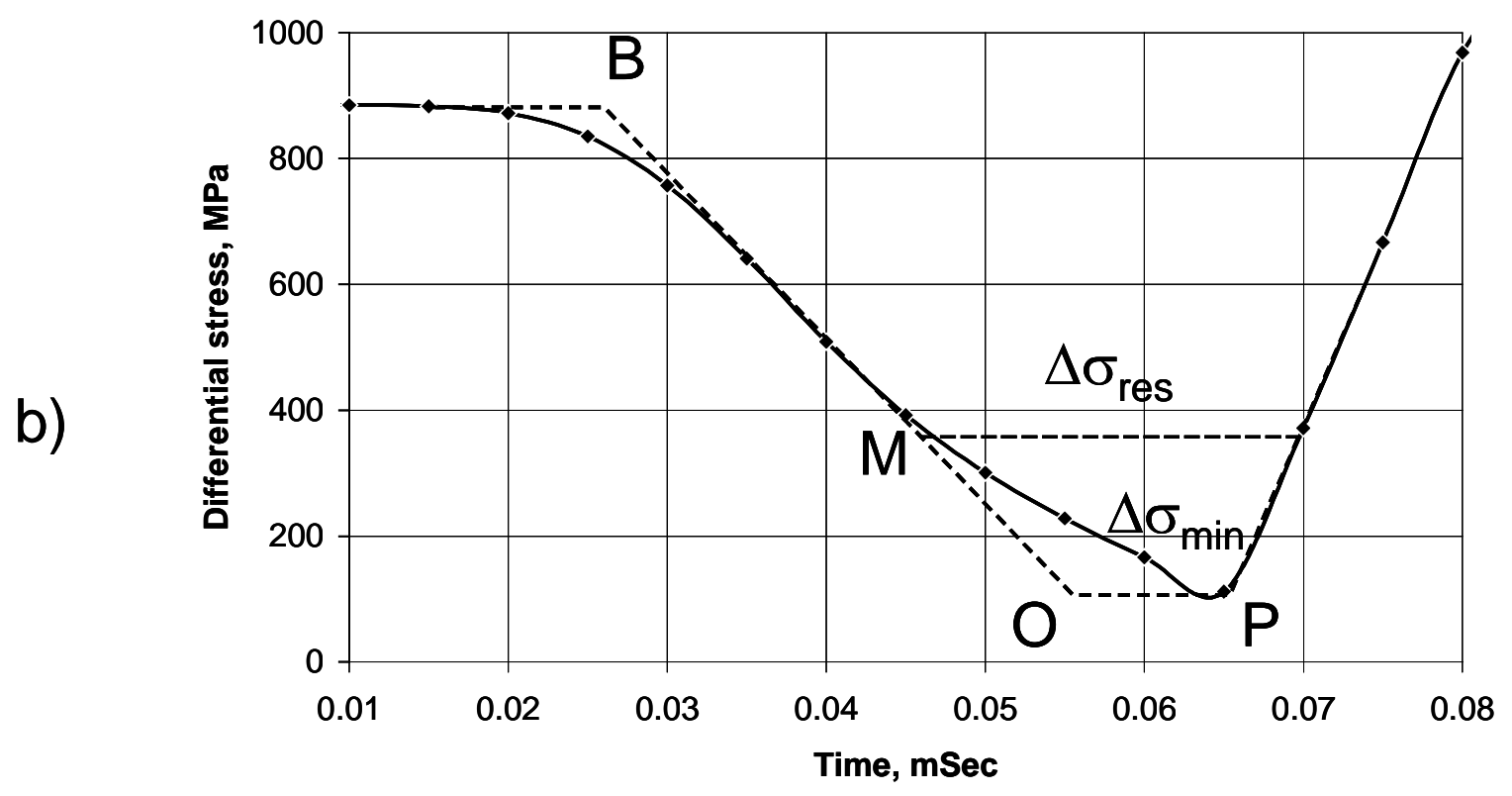

Figure 2A. Curves of differential stress versus time for specimen failed at confining pressure $100 \mathrm{MPa}$.

a) - Total curve; b) - Fragment of the curve 

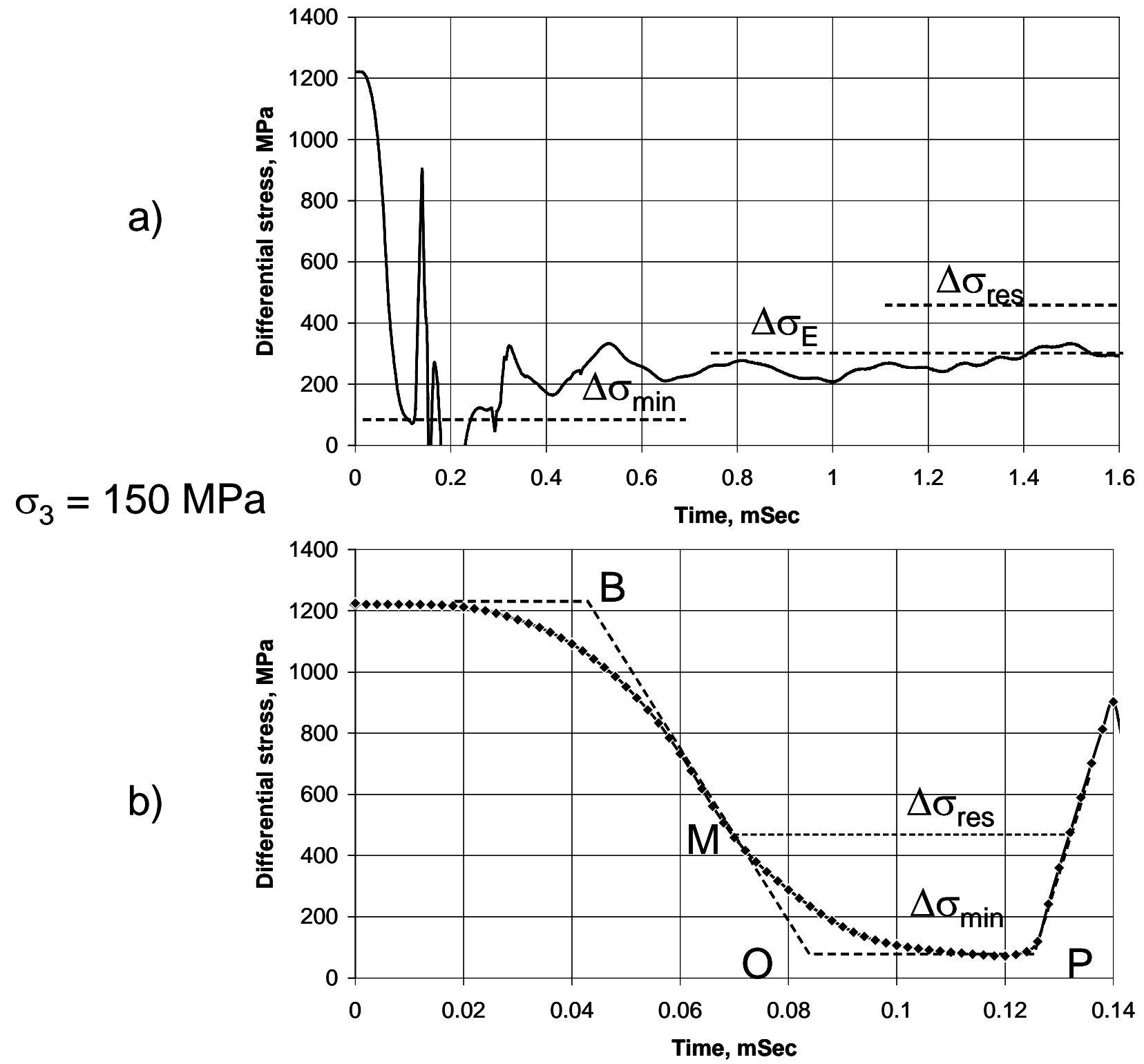

Figure 3A. Curves of differential stress versus time for specimen failed at confining pressure $150 \mathrm{MPa}$.

a) - Total curve; b) - Fragment of the curve 

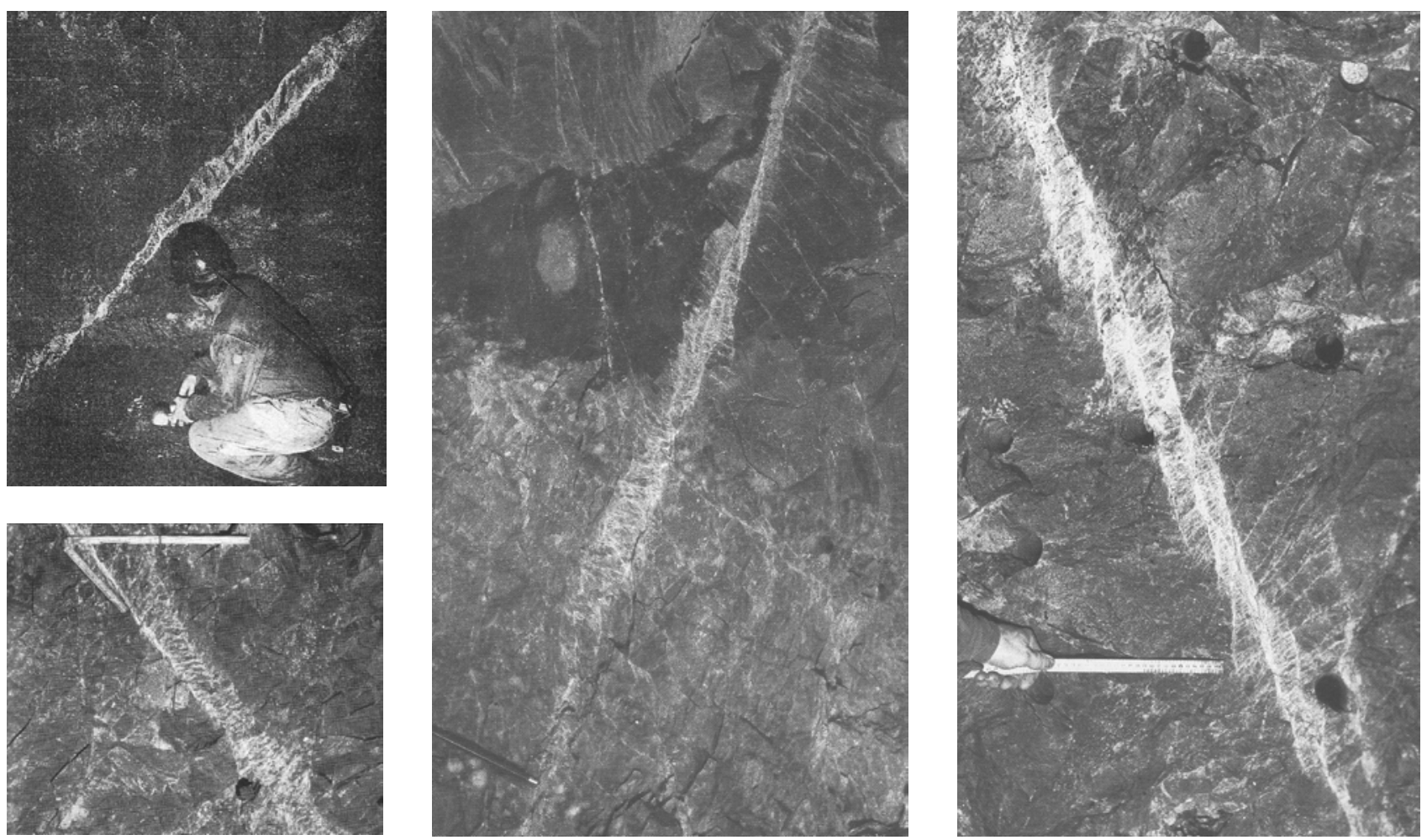

Figure 8. Shear fractures involving elements of the frictionless mechanism (From Ortlepp, 1997) 